\title{
Telomerase regulation: A key to inhibition? (Review)
}

\author{
DIEGO L. MENGUAL GÓMEZ, HERNÁN G. FARINA and DANIEL E. GÓMEZ \\ Laboratory of Molecular Oncology, Science and Technology Department, \\ National University of Quilmes, Buenos Aires, Argentina \\ Received May 27, 2013; Accepted July 5, 2013
}

DOI: $10.3892 /$ ijo.2013.2104

\begin{abstract}
Telomerase has been recognized as a common factor in most tumor cells, and in turn a distinctive feature with respect to non-malignant cells. This feature has made telomerase a promising target for cancer therapy. Telomerase studies revealed that it is a multi-subunit complex possessing different levels of regulation, including control of expression, phosphorylation state, assembly and transportation to sites of activity. Thus, we emphasize that targeting telomerase expression or activity is not the only way to shorten telomeres, induce cell senescence and apoptosis. Therefore, there are multiple sites capable of allowing the modulation of its enzymatic activity. In the development of strategies based on the regulation of telomerase activity the understanding of the mechanisms regulating their subunits is essential. Based on this, in this review we summarize the current state of knowledge of some regulatory mechanisms of the components of the telomerase complex, and hypothetize their potential therapeutic application against cancer.
\end{abstract}

\section{Contents}

1. Telomere structure and function

2. Telomerase holoenzyme

3. TERT regulation

4. Nuclear transport of TR

5. Assembly of telomerase complex

6. Regulation of telomerase by telomere binding

7. Conclusion/summary

\section{Telomere structure and function}

Telomeres are regions of repetitive nucleotide sequences at each end of chromosomes, this region is a repetition

Correspondence to: Dr Daniel Gómez, Laboratory of Molecular Oncology, Science and Technology Department, National University of Quilmes, Roque Saenz Peña 352 (1876), Buenos Aires, Argentina E-mail: degomez@unq.edu.ar

Key words: telomerase, telomeres, cancer, telomerase activity regulation of a guanine-rich sequences. In humans, telomeres are comprised of a repetitive TTAGGG sequence with a 3' G-rich single-stranded overhang $(1,2)$. The ends of telomeres form a lariat-like structure called t-loop (3), which is postulated to be formed by strand invasion of the $3^{\prime}$ single strand overhang into the preceding double stranded telomeric DNA that is then stabilized by telomeric proteins (4). A six-protein complex known as 'shelterin' has remarkable specificity for telomeres and some members of the complex specifically binds to telomeric DNA. These proteins are: telomere repeat binding factor 1 (TRF1), telomere repeat binding factor 2 (TRF2), repressor/activator protein 1 (RAP1), protection of telomeres 1 (POT1), TRF1 interacting nuclear factor 2 (TIN2), and TPP1 [also known POT1 and TIN2 organizing protein (5-8)]. The functions of shelterin protein components are to maintain telomere length, promote t-loop formation, recruit telomerase to telomeric ends, and protect the ends of chromosomes from being recognized as DNA damage $(5,8,9)$. The cell replication apparatus is not able to provide for complete replication of chromosome ends; also, telomeres are subject to the action of nucleases and other deleterious factors. As a result, telomeres shorten during each cell division. In most organisms the main mechanism of telomere length maintenance is completion of DNA telomere repeats by telomerase (10). In other cases there is a non-telomerase mechanism, known as alternative lengthening of telomeres (ALT) which involves the use of a DNA template (11). Most cancer cells have a chromosome end renewal mechanism involving the telomerase complex, which utilizes its integral RNA molecule as a template for reverse transcription of new telomeric DNA. In normal, healthy cells telomerase activity is mostly limited to embryonic cells, adult germline cells, and stem cells but is virtually absent in somatic cells (12) while it is rather common in the vast majority of cancer cells $(13,14)$, providing important targets for detection and treatment (Fig. 1).

\section{Telomerase holoenzyme}

The telomerase is a specific reverse transcriptase responsible for the maintenance of telomere length in most mammals; this enzyme was initially identified in ciliates (15). The human telomerase is comprised of two main subunits, the RNA template and the catalytic enzyme (16). The telomerase RNA template (hTR or hTERC) contains a complementary sequence to the human telomere that serves as the base for replication of short repetitive telomere sequences d(TTAGGG) (17). The 


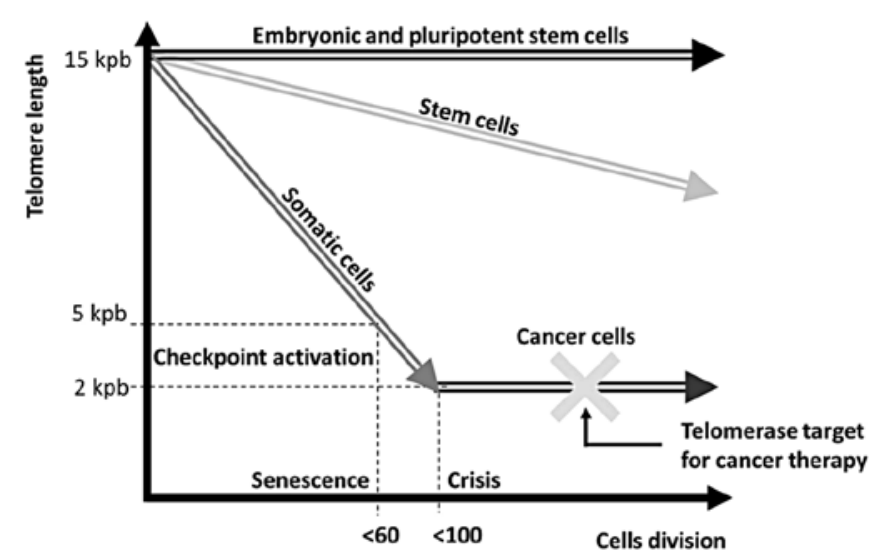

Figure 1. Telomere lengths vs cell divisions. The cells that have a constitutive telomerase activity (embryonic and pluripotent stem cells) may completely maintain telomere lengths. Stem cells transiently express telomerase or express moderate amounts of telomerase maintaining partially telomeric length, with increased age and cell divisions, telomeres continue to shorten in these cells. Normal somatic cells that do not express telomerase have their telomeres shorten with each cell division. Cancer cells which reactivate or upregulate telomerase fully maintain telomeres but generally at reduced lengths. This feature has made telomerase a promising target for cancer therapy.

extension of telomeres is completed through the catalytic component, its reverse transcriptase (hTERT) (18). Along with these two main components are additional telomere/ telomerase associated proteins. These accessory proteins regulate telomerase biogenesis, their subcellular localization, and function in vivo. Formation of the functional holoenzyme complex requires associated proteins including the box H/ACA small nucleolar RNA proteins: dyskerin, nucleolar protein 10 (NOP10), non-histone protein 2 (NHP2), and glycine-arginine rich 1 (GAR1) (19). Other proteins involved in the telomerase complex are pontin/reptin and telomerase Cajal body protein 1 (TCAB1) (20). Pontin and reptin are two ATPases, which interact with TERT in the $S$ phase of the cell cycle, showing a TERT dependent regulation of cell cycle. Pontin and reptin interact with TERT, suggesting that pontin and reptin also serve to assemble or remodel a telomerase complex containing TERT. This process may occur in a stepwise fashion in which pontin and reptin facilitate assembly of TERT with a TR-dyskerin RNP, or remodel this maturing telomerase complex (21). Finally the factor TCAB1 regulates the subcellular location of telomerase (22).

Telomerase levels are regulated at every step of protein and RNA processing, as well as at the level of complex assembly and subcellular localization (23). Telomerase activity at the telomere is also regulated at the level of telomerase recruitment to the telomere. While the exact mechanism of telomerase recruitment is still not fully known, it is likely part of a negative feedback loop created by shelterin proteins bound at the telomere that serve as negative regulators of telomerase extension of telomeres (reviewed in ref. 24). The prevailing model of shelterin mediated telomere length regulation is that longer telomeres recruit more shelterin complex, which in turn limits future telomerase elongation. This negative feedback loop is thought to be responsible for the stable telomere length found in cancer cells, and is likely responsible for at least partially maintaining telomere length homeostasis in germ cells and other stem-like cells in which telomerase is active (25). Thus, it would be possible that other mechanisms regulating telomerase recruitment or processivity exist depending on whether cells are at equilibrium conditions versus non-equilibrium conditions.

\section{TERT regulation}

Intensive studies of telomerase functioning in human cells gave new perspectives on the mechanism of senescence, stem cells and cancer therapy. The studies show that numerous enzymes are required for telomerase functioning that facilitate new approaches for inhibiting telomerase in cancer treatment. Probably there are still numerous unrevealed proteins that contribute to regulation of such a dynamic complex that still are to be discovered. As already reported, TERT splice variants may be expressed in normal, pre-crisis and alternative lengthening of telomeres cells (ALT) that lack detectable telomerase activity (26-28). Thus, transcriptional control of TERT is supposed to play a crucial role in the complex regulation of telomerase activity. Post-translational regulation of telomerase activity can occur via reversible phosphorylation of TERT catalytic subunit at specific serine/ threonine or tyrosine residues. Due to multiple kinase and phosphatase activators and inhibitors the telomerase phosphorylation status may affect its structure, localization and enzyme activity (29). Numerous non-specific phosphorylation sites within TERT protein are postulated but only a few of them appear to be the key residues, and their phosphorylation influences telomerase activity (activation and inhibition) (30). Specific phosphorylation site at TERT is present at the proline rich region (29). It was revealed that the contribution of c-Abl tyrosine kinase to TERT phosphorylation at specific tyrosine residues led to decreased telomerase activity. It was shown that overexpression of c-Abl inhibited cell growth by causing cell cycle arrest (30). Because of the role of c-Abl in stress response to DNA damage, exposure of cells to ionizing radiation led to a significant increase in TERT phosphorylation by c-Abl. It was also demonstrated that $\mathrm{c}-\mathrm{Abl}$ phosphorylated TERT is leading to inhibition of telomerase activity and decrease in telomere length (31) suggesting a direct association between c-Abl and TERT. In conclusion, TERT expression is regulated at both, transcriptional and post-transcriptional levels, with the alternative splicing of TERT also involved in the control of telomerase activity. However, contradictive reports concern the correlation of telomere length with telomerase activity or TERT expression in different cells which might confirm the tissue-specificity of those regulatory mechanisms.

\section{Nuclear transport of TR}

As shown, translocation of TR and TERT is regulated and multiple nuclear structures participate in transport and biogenesis of telomerase (32). Throughout most of the cell cycle TR is present in Cajal bodies (CBs) that act as its transmitters to telomeres (33). These subnuclear structures are general sites of RNP assembly and RNA modification (34). In contrary to TR, TERT is located in distinct nucleoplasmic 
foci and therefore, the two main subunits of telomerase are separated during almost the whole cell cycle. In early $\mathrm{S}$ phase TERT is translocated to nucleoli. At the same time CBs containing TR accumulate at the periphery of nucleoli. TR accumulates at the pole of CBs that precedes localization to telomeres in mid-S phase when CBs deliver telomerase to individual telomeres. Furthermore, it was revealed that the same kinases and phosphatases that act during S-phase may modify telomerase subunits (32). However, the mechanisms involved in targeting and accumulation of TR are not fully understood (35). To date, within telomerase RNA molecule the CAB box and H/ACA motif has been identified to influence the TR translocation to CBs and nucleoli $(36,37)$. In the same way, one of TERT domains is known to mediate nucleolar translocation $(38,39)$.

\section{Assembly of telomerase complex}

Human telomerase assembly occurs by an energy-dependent complex mechanism that involves first the stabilization of TR and then its association with TERT $(40,41)$. Only TERT and TR are necessary to gain telomerase activity in vitro. However, in vivo telomerase complex is composed of additional multiple proteins, that facilitate the enzyme to act (42). Similarly to the transport of TERT to the nucleus, assembly of the telomerase complex may be regulated during the cell cycle. Telomerase assembly could take place during $\mathrm{S}$ phase and it is disassembled probably during $\mathrm{M}$ phase (35). Prevention of premature binding of the essential telomerase subunits (TERT and TR) is possible due to different sites of their compartmentalization and keeping them away from their substrates (telomeres) (32). Thus, two telomerase assembling sites are possible during $\mathrm{S}$ phase at the telomere ends (43) or in CBs (32). It has been suggested that survival of motor neuron (SMN) complex, an RNP assembly factor present in CBs, takes part in telomerase biogenesis. It was demonstrated that TR is associated with GAR1, a protein which interacts with SMN complex (44). However, further studies are needed to establish exactly where the telomerase assembly occurs. Recent studies showed that the localization of TR in CBs and near telomeres depends onTERT. This suggests that TR assembles a complex with TERT and then both proteins are transported to telomeres. Alternatively, TERT is supposed to indirectly influence the trafficking of TR or a transient interaction of the two components that contribute to TR localization (45).

The $3^{\prime}$ end of the vertebrate TR contains two stem-loop structures separated by a box $\mathrm{H}$ and box ACA moiety, aptly named the H/ACA domain (36). Each of the two structures in the TR H/ACA domain binds a copy of the protein complex formed by dyskerin, NOP10, NHP2 and GAR1 proteins. This protein complex is important for RNA maturation, 3 ' processing and RNP biogenesis (46). CB location of TR is dependent on the TCAB1 protein binding to the CAB (Cajal body box) (47). Dyskerin is the mammalian ortholog of the archaeal H/ACA RNA pseudouridine synthase which contains the catalytic TruB domain and the pseudouridine synthase and archaeosine transglycosylase (PUA) domain involved in RNA modification (48). NOP10 is a small basic protein with a conserved zinc ribbon domain in the $\mathrm{N}$-terminal region. This protein does not directly bind to the RNA, and instead binds to dyskerin $(49,50)$. NHP2 is another small basic protein, which binds to the RNA (49-51). GAR1 is defined by, and named for, the glycine and arginine rich (GAR) domains which flank the highly conserved central domain (50). As with NOP10, GAR1 also does not directly bind to the RNA and instead binds to the dyskerin. GAR1 is not required for H/ACA snoRNP stability in vivo or snoRNP assembly in vitro $(51,52)$. While dyskerin bound H/ACA snoRNAs localize to both nucleoli and CBs, TCAB1 bound scaRNAs exclusively localize to CBs. TCAB1 is responsible for TR localization to CBs since the depletion of TCAB1 alters the localization of the TR to nucleoli (47).

Numerous unique mutations have been identified within the DKC1 gene, encoding for dyskerin $(53,54)$. Mutations in a limited number of families have also been reported in NOLA2, encoding for NHP2 (55); and NOLA3, encoding for NOP10 (56). These mutations retain wild-type telomerase activity in vitro while reducing the amount of active telomerase within the cell. No reports of mutations within NOLA1, encoding for GAR1, have been linked to telomere-mediated disorders. Mutations within the DKC1 gene are associated with X-linked recessive dyskeratosis congenita (DC) (57), while mutations in the NOLA2 and NOLA3 genes correlate to autosomal recessive DC $(58,59)$. Dyskerin and other associated proteins are crucial for ribosomal, as well as telomerase biogenesis (58). However, mutations within these genes appear to have no significant negative effect upon ribosome maturation in human cells (59). Since the discovery of TCAB1 and its gene, WRD79, there has been a report of mutations linked to two cases of autosomal recessive DC. These mutations produce defects in TR trafficking, reducing the amount of active enzyme (22).

While the intricate details of telomerase RNP assembly have yet to be fully elucidated, much progress has been made in uncovering many of the steps necessary for individual component maturation and the assembly of these components into an active ribonucleoprotein enzyme. TERT protein expression follows the canonical mRNA transcription, maturation and cytoplasmic translation. The TERT protein is then recruited to nucleoli and then CBs for RNP assembly $(38,60)$. The accumulation of TERT in the nucleoli reduces the levels of active telomerase, supposedly by sequestering TERT from TR $(61,62)$. TR begins as a precursor RNA polymerase II transcript capped by trimethyl-guanosine (TMG) (63). Binding by RNA Helicase associated with AU-rich element (RHAU) to the 5' end resolves the G-quadruplex structure while binding dyskerin and other proteins to the $3^{\prime}$ end, trim and internally modify the RNA to produce a mature TR (64). The initial binding of dyskerin to the TR, and other H/ACA snoRNA species, relies on the sequential binding of snoRNA H/ACA family quantitative accumulation 1 (SHQ1), followed by nuclear assembly factor 1 (NAF1) to dyskerin. NAR1 is exchanged for GAR1 and SHQ1 is lost prior to the localization of the mature TR to CBs (65). TCAB1 binding is thought to then direct the mature TR to CBs $(47,65)$. TERT is then localized near the CBs where telomerase RNP assembly occurs (60). The assembled telomerase localize to the telomere for the nucleotide addition to the process (66). The regulation of each component of the telomerase holoenzyme 
has implications for the accumulation of active telomerase within the cell (67).

ATPases and DNA helicases pontin and reptin reveal an essential role in telomerase assembly. The amount of TERT bound to pontin and reptin peaks in $\mathrm{S}$ phase (21). When the two pivotal subunits of telomerase are stabilized and bound with auxiliary proteins the TERT and TR dimerization occurs. Two regions of TR are necessary for its binding with TERT: the template region (nucleotides 44-186) and a putative double hairpin element in the 50 stem of the H/ACA domain, where TR stabilizing H/ACA proteins bind (nucleotides 243-326) (68).

\section{Regulation of telomerase by telomere binding}

Interaction of telomerase with numerous telomere binding proteins (TBP) that may influence telomerase enzyme activity is considered another form of telomerase activity regulation. It is supposed that binding some of them to telomeres, therefore making it impossible for telomerase to access the chromosome ends, is an indirect way of regulation (69). Three-state model of telomere length regulation were studied (70). Firstly, POT1 is directly bound at the 3 end of telomere and associates with TPP1. This POT1-TPP1 position prevents binding of telomerase to chromosome ends (5). Secondly, TPP1-POT1 association enhanced POT1 affinity for telomeric sDNA and TPP1 associates with the telomerase, providing a physical link between telomerase and the shelterin complex (71). According to this model, in the next state these proteins are removed from their binding sites by an unidentified mechanism. Posttranslational modification or disruption of shelterin might be involved in the process. Thistly, released POT1-TPP1 complex may serve as an activator of telomerase during telomere extension. When elongated, telomere reaches a certain threshold, the newly synthesized repeats bind shelterin complexes and the $3^{\prime}$ end of the overhang is re-bound by POT1-TPP1. This causes telomerase inhibition and return of the telomere to the first state of the complex (71). TRF1 and TRF2 are the main proteins responsible for telomerase negative feedback control in mammals. They are bound to double stranded DNA at T-loop, which is a 'closed' state of telomere, which telomerase cannot access and therefore extends the telomere terminus. TRF1 and TRF2 act as negative regulators of telomere length because they are involved in T-loop formation $(72,73)$. TRF1 and TRF2 were shown to act in cis to repress telomere elongation. TRF1 was reported to repress telomerase action on telomeres while, on the contrary, TRF2 appears to activate a telomeric degradation without showing any influence on telomerase (74). Other proteins with negative-feedback regulation of telomere length have been identified in human cells. The proteins acting on TRF1 are tankyrase 1 and 2 (TANK 1 and 2), TIN2, PINX1, three TRF1-interacting factors but also hRAP1 which interacts with TRF2 $(9,74)$. PINX1 can inhibit telomerase by forming a stable complex with catalytic subunit of telomerase and TRF1 molecule. It binds with TERT by its telomerase inhibitory domain (TID) placed at $\mathrm{C}$ terminal 74 aa (22). The human repressor activator protein 1 (hRap1) was identified as a protein that specifically interacts with TRF2 and negatively regulates telomere length in vivo.

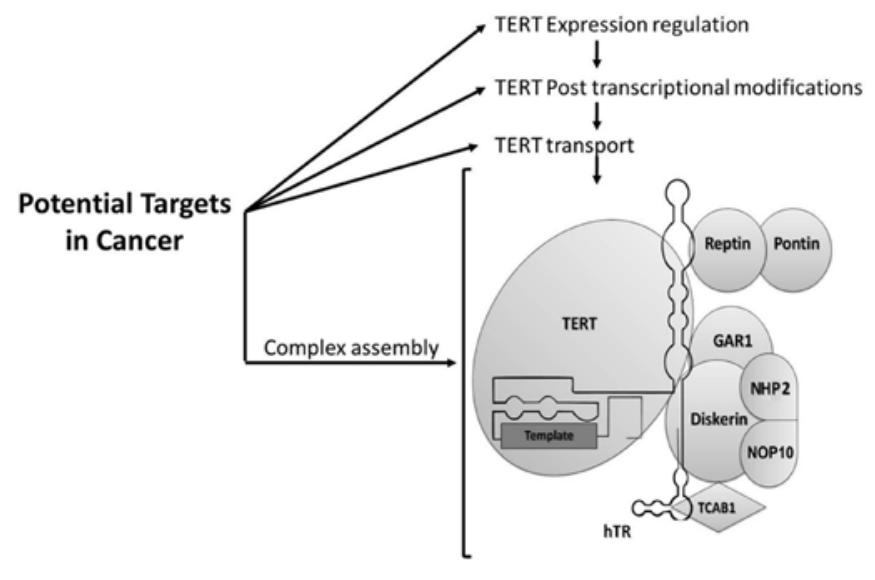

Figure 2. Different steps in the telomerase regulation. These sites of regulation could be targets of telomerase activity in cancer therapies.

\section{Summary and conclusions}

Numerous studies on the behavior of telomerase, created a solid body of evidence about the mechanisms of senescence, and its activity in tumor cells. These studies showed the role of accessory proteins in the functionally active telomerase complex. Since accessory proteins regulate telomerase there is a chance of creating new approaches for the indirect inhibition of telomerase in cancer treatment. In conclusion, telomerase activity contains multiple factors that allow the regulation, including the expression of TERT levels, posttranscriptional modifications, transportation and location and finally conformation and interactions with accessory proteins during assembly of the telomerase complex (Fig. 2) providing possible targets to be approached in the strategy of affecting this enzyme for cancer treatment. Many of these processes have been studied in detail, creating the basis to find molecules that regulate telomerase activity. Imetelstat is a synthetic molecule that binds to the telomerase RNA component sequence (hTR) in the active site region of telomerase preventing its action (75). Curcumin has been shown to decrease the activity of telomerase in several types of cancer (76-78). This inhibition may be due to the impossibility of the translocation to the nucleus by dissociating Hsp-90 and p23 chaperones from TERT (79). Sulforaphane has been shown to cause a decrease in the expression of TERT and TERT phosphorylation, preventing nuclear translocation (80). However, there is little evidence on how we can modulate telomerase activity by targeting the major components of the complex (diskerin, Gar1, Nop10, and NHP2), leaving a window of opportunity to the creation and application of indirect anti-telomeric therapies in cancer.

\section{Acknowledgements}

This study was supported by Grants from Quilmes National University, CONICET and ANPCyT (Argentina). D.E.G. and H.G.F. are researchers from CONICET. D.E.G. is a member of the National Cancer Institute of Argentina. 


\section{References}

1. Blackburn EH: Structure and function of telomeres. Nature 350: 569-573, 1991.

2. Moyzis RK, Buckingham JM, Cram LS, et al: A highly conserved repetitive DNA sequence, (TTAGGG)n, present at the telomeres of human chromosomes. Proc Natl Acad Sci USA 85: 6622-6626, 1988

3. Griffith JD, Comeau L, Rosenfield S, et al: Mammalian telomeres end in a large duplex loop. Cell 97: 503-514, 1999.

4. Greider CW: Telomeres do D-loop-T-loop. Cell 97: 419-422, 1999.

5. De Lange T: Shelterin: the protein complex that shapes and safeguards human telomeres. Genes Dev 19: 2100-2110, 2005.

6. Neidle S: Human telomeric G-quadruplex: the current status of telomeric G-quadruplexes as therapeutic targets in human cancer. FEBS J 277: 1118-1125, 2010.

7. O'Sullivan RJ and Karlseder J: Telomeres: protecting chromosomes against genome instability. Nat Rev Mol Cell Biol 11: 171-181, 2010.

8. Palm W and de Lange T: How shelterin protects mammalian telomeres. Annu Rev Genet 42: 301-334, 2008.

9. Smogorzewska A and de Lange T: Regulation of telomerase by telomeric proteins. Annu Rev Biochem 73: 177-208, 2004.

10. Greider $\mathrm{CW}$ and Blackburn EH: The telomere terminal transferase of Tetrahymena is a ribonucleoprotein enzyme with two kinds of primer specificity. Cell 51: 887-898, 1987.

11. Bryan TM and Reddel RR: Telomere dynamics and telomerase activity in in vitro immortalised human cells. Eur J Cancer 33: 767-773, 1997.

12. Broccoli D, Young JW and de Lange T: Telomerase activity in normal and malignant hematopoietic cells. Proc Natl Acad Sci USA 92: 9082-9086, 1995.

13. Ryan KM and Birnie GD: Cell-cycle progression is not essentia for c-Myc to block differentiation. Oncogene 14: 2835-2843, 1997.

14. Wu KJ, Grandori C, Amacker M, et al: Direct activation of TERT transcription by c-MYC. Nat Genet 21: 220-224, 1999.

15. Greider CW and Blackburn EH: Identification of a specific telomere terminal transferase activity in Tetrahymena extracts. Cell 43: 405-413, 1985

16. Mason M, Schuller A and Skordalakes E: Telomerase structure function. Curr Opin Struct Biol 21: 92-100, 2011.

17. Feng J, Funk WD, Wang SS, et al: The RNA component of human telomerase. Science 269: 1236-1241, 1995.

18. Morin GB: The human telomere terminal transferase enzyme is a ribonucleoprotein that synthesizes TTAGGG repeats. Cell 59: 521-529, 1989.

19. Ly H: Genetic and environmental factors influencing human diseases with telomere dysfunction. Int J Clin Exp Med 2: 114-130, 2009

20. Fu D and Collins K: Purification of human telomerase complexes identifies factors involved in telomerase biogenesis and telomere length regulation. Mol Cell 28: 773-785, 2007.

21. Venteicher AS, Meng Z, Mason PJ, Veenstra TD and Artandi SE: Identification of ATPases pontin and reptin as telomerase components essential for holoenzyme assembly. Cell 132: 945-957, 2008

22. Zhong F, Savage SA, Shkreli M, et al: Disruption of telomerase trafficking by TCAB1 mutation causes dyskeratosis congenita. Genes Dev 25: 11-16, 2011

23. Kelleher C, Teixeira MT, Forstemann $\mathrm{K}$ and Lingner $\mathrm{J}$ : Telomerase: biochemical considerations for enzyme and substrate. Trends Biochem Sci 27: 572-579, 2002.

24. De Boeck G, Forsyth RG, Praet M and Hogendoorn PC: Telomere-associated proteins: cross-talk between telomere maintenance and telomere-lengthening mechanisms. J Pathol 217: 327-344, 2009.

25. Forsyth NR, Wright WE and Shay JW: Telomerase and differentiation in multicellular organisms: turn it off, turn it on, and turn it off again. Differentiation 69: 188-197, 2002.

26. Kilian A, Bowtell DD, Abud HE, et al: Isolation of a candidate human telomerase catalytic subunit gene, which reveals complex splicing patterns in different cell types. Hum Mol Genet 6: 2011-2019, 1997.

27. Ulaner GA, Hu JF, Vu TH, Giudice LC and Hoffman AR Telomerase activity in human development is regulated by human telomerase reverse transcriptase (hTERT) transcription and by alternate splicing of hTERT transcripts. Cancer Res 58: 4168-4172, 1998
28. Ulaner GA, Hu JF, Vu TH, Oruganti H, Giudice LC and Hoffman AR: Regulation of telomerase by alternate splicing of human telomerase reverse transcriptase (hTERT) in norma and neoplastic ovary, endometrium and myometrium. Int J Cancer 85: 330-335, 2000.

29. Cong YS, Wright WE and Shay JW: Human telomerase and its regulation. Microbiol Mol Biol Rev 66: 407-425, 2002.

30. Sawyers CL, McLaughlin J, Goga A, Havlik M and Witte O The nuclear tyrosine kinase c-Abl negatively regulates cell growth. Cell 77: 121-131, 1994.

31. Kharbanda S, Kumar V, Dhar S, et al: Regulation of the hTERT telomerase catalytic subunit by the c-Abl tyrosine kinase. Curr Biol 10: 568-575, 2000.

32. Tomlinson RL, Ziegler TD, Supakorndej T, Terns RM and Terns MP: Cell cycle-regulated trafficking of human telomerase to telomeres. Mol Biol Cell 17: 955-965, 2006

33. Jady BE, Richard P, Bertrand E and Kiss T: Cell cycle-dependent recruitment of telomerase RNA and Cajal bodies to human telomeres. Mol Biol Cell 17: 944-954, 2006.

34. Cioce $\mathrm{M}$ and Lamond AI: Cajal bodies: a long history of discovery. Annu Rev Cell Dev Biol 21: 105-131, 2005.

35. Wojtyla A, Gladych M and Rubis B: Human telomerase activity regulation. Mol Biol Rep 38: 3339-3349, 2011.

36. Jady BE, Bertrand $\mathrm{E}$ and Kiss T: Human telomerase RNA and box H/ACA scaRNAs share a common Cajal body-specific localization signal. J Cell Biol 164: 647-652, 2004.

37. Lukowiak AA, Narayanan A, Li ZH, Terns RM and Terns MP The snoRNA domain of vertebrate telomerase RNA functions to localize the RNA within the nucleus. RNA 7: 1833-1844, 2001.

38. Etheridge KT, Banik SS, Armbruster BN, et al: The nucleolar localization domain of the catalytic subunit of human telomerase. J Biol Chem 277: 24764-24770, 2002.

39. Yang $\mathrm{Y}$, Chen $\mathrm{Y}$, Zhang $\mathrm{C}$, Huang $\mathrm{H}$ and Weissman SM: Nucleolar localization of hTERT protein is associated with telomerase function. Exp Cell Res 277: 201-209, 2002.

40. Aisner DL, Wright WE and Shay JW: Telomerase regulation: not just flipping the switch. Curr Opin Genet Dev 12: 80-85, 2002.

41. Collins K: Physiological assembly and activity of human telomerase complexes. Mech Ageing Dev 129: 91-98, 2008.

42. McEachern MJ, Krauskopf A and Blackburn EH: Telomeres and their control. Annu Rev Genet 34: 331-358, 2000

43. Taggart AK, Teng SC and Zakian VA: Estlp as a cell cycleregulated activator of telomere-bound telomerase. Science 297 1023-1026, 2002

44. Bachand F, Boisvert FM, Cote J, Richard S and Autexier C: The product of the survival of motor neuron (SMN) gene is a human telomerase-associated protein. Mol Biol Cell 13: 3192-3202, 2002.

45. Tomlinson RL, Abreu EB, Ziegler T, et al: Telomerase reverse transcriptase is required for the localization of telomerase RNA to cajal bodies and telomeres in human cancer cells. Mol Biol Cell 19: 3793-3800, 2008

46. Li H: Unveiling substrate RNA binding to H/ACA RNPs: one side fits all. Curr Opin Struct Biol 18: 78-85, 2008

47. Venteicher AS, Abreu EB, Meng Z, et al: A human telomerase holoenzyme protein required for Cajal body localization and telomere synthesis. Science 323: 644-648, 2009.

48. Cheng $X$ and Roberts RJ: AdoMet-dependent methylation, DNA methyltransferases and base flipping. Nucleic Acids Res 29: 3784-3795, 2001.

49. Hamma T, Reichow SL, Varani G and Ferre-D'Amare AR: The Cbf5-Nop10 complex is a molecular bracket that organizes box H/ACA RNPs. Nat Struct Mol Biol 12: 1101-1107, 2005.

50. Pogacic V, Dragon F and Filipowicz W: Human H/ACA small nucleolar RNPs and telomerase share evolutionarily conserved proteins NHP2 and NOP10. Mol Cell Biol 20: 9028-9040, 2000

51. Maiorano D, Brimage LJ, Leroy D and Kearsey SE: Functional conservation and cell cycle localization of the Nhp2 core component of $\mathrm{H}+$ ACA snoRNPs in fission and budding yeasts. Exp Cell Res 252: 165-174, 1999.

52. Girard JP, Caizergues-Ferrer M and Lapeyre B: The SpGAR1 gene of Schizosaccharomyces pombe encodes the functional homologue of the snoRNP protein GAR1 of Saccharomyces cerevisiae. Nucleic Acids Res 21: 2149-2155, 1993

53. Cossu F, Vulliamy TJ, Marrone A, Badiali M, Cao A and Dokal I: A novel DKC1 mutation, severe combined immunodeficiency (T+B-NK- SCID) and bone marrow transplantation in an infant with Hoyeraal-Hreidarsson syndrome. Br J Haematol 119: $765-768,2002$ 
54. Wong JM, Kyasa MJ, Hutchins L and Collins K: Telomerase RNA deficiency in peripheral blood mononuclear cells in X-linked dyskeratosis congenita. Hum Genet 115: 448-455, 2004.

55. Vulliamy T, Beswick R, Kirwan M, et al: Mutations in the telomerase component NHP2 cause the premature ageing syndrome dyskeratosis congenita. Proc Natl Acad Sci USA 105: 8073-8078, 2008.

56. Walne AJ, Vulliamy T, Marrone A, et al: Genetic heterogeneity in autosomal recessive dyskeratosis congenita with one subtype due to mutations in the telomerase-associated protein NOP10. Hum Mol Genet 16: 1619-1629, 2007.

57. Heiss NS, Knight SW, Vulliamy TJ, et al: X-linked dyskeratosis congenita is caused by mutations in a highly conserved gene with putative nucleolar functions. Nat Genet 19: 32-38, 1998.

58. Meier UT: The many facets of H/ACA ribonucleoproteins. Chromosoma 114: 1-14, 2005.

59. Parry EM, Alder JK, Lee SS, et al: Decreased dyskerin levels as a mechanism of telomere shortening in X-linked dyskeratosis congenita. J Med Genet 48: 327-333, 2011.

60. Tomlinson RL, Li J, Culp BR, Terns RM and Terns MP: A Cajal body-independent pathway for telomerase trafficking in mice. Exp Cell Res 316: 2797-2809, 2010.

61. Lin J, Jin R, Zhang B, et al: Nucleolar localization of TERT is unrelated to telomerase function in human cells. J Cell Sci 121: 2169-2176, 2008.

62. Wong JM, Kusdra L and Collins K: Subnuclear shuttling of human telomerase induced by transformation and DNA damage. Nat Cell Biol 4: 731-736, 2002.

63. Gallardo F and Chartrand P: Telomerase biogenesis: The long road before getting to the end. RNA Biol 5: 212-215, 2008.

64. Collins K: The biogenesis and regulation of telomerase holoenzymes. Nat Rev Mol Cell Biol 7: 484-494, 2006.

65. Grozdanov PN, Roy S, Kittur N and Meier UT: SHQ1 is required prior to NAF1 for assembly of H/ACA small nucleolar and telomerase RNPs. RNA 15: 1188-1197, 2009.

66. Abreu E, Aritonovska E, Reichenbach P, et al: TIN2-tethered TPP1 recruits human telomerase to telomeres in vivo. Mol Cell Biol 30: 2971-2982, 2010

67. Cifuentes-Rojas C and Shippen DE: Telomerase regulation. Mutat Res 730: 20-27, 2012.

68. Collins K and Mitchell JR: Telomerase in the human organism. Oncogene 21: 564-579, 2002
69. Venteicher AS and Artandi SE: TCAB1: driving telomerase to Cajal bodies. Cell Cycle 8: 1329-1331, 2009.

70. Wang F, Podell ER, Zaug AJ, et al: The POT1-TPP1 telomere complex is a telomerase processivity factor. Nature 445 : 506-510, 2007.

71. Xin H, Liu D, Wan M, et al: TPP1 is a homologue of ciliate TEBP-beta and interacts with POT1 to recruit telomerase. Nature 445: 559-562, 2007.

72. Shore D and Bianchi A: Telomere length regulation: coupling DNA end processing to feedback regulation of telomerase. EMBO J 28: 2309-2322, 2009.

73. Smogorzewska A, van Steensel B, Bianchi A, et al: Control of human telomere length by TRF1 and TRF2. Mol Cell Biol 20: 1659-1668, 2000

74. Ancelin K, Brunori M, Bauwens S, et al: Targeting assay to study the cis functions of human telomeric proteins: evidence for inhibition of telomerase by TRF1 and for activation of telomere degradation by TRF2. Mol Cell Biol 22: 3474-3487, 2002.

75. Roth A, Harley CB and Baerlocher GM: Imetelstat (GRN163L)-telomerase-based cancer therapy. Recent Results Cancer Res 184: 221-234, 2010.

76. Chakraborty S, Ghosh U, Bhattacharyya NP, Bhattacharya RK and Roy M: Inhibition of telomerase activity and induction of apoptosis by curcumin in K-562 cells. Mutat Res 596: 81-90, 2006.

77. Mukherjee Nee Chakraborty S, Ghosh U, Bhattacharyya NP, Bhattacharya RK, Dey S and Roy M: Curcumin-induced apoptosis in human leukemia cell HL-60 is associated with inhibition of telomerase activity. Mol Cell Biochem 297: 31-39, 2007.

78. Ramachandran C, Fonseca HB, Jhabvala P, Escalon EA and Melnick SJ: Curcumin inhibits telomerase activity through human telomerase reverse transcritpase in MCF-7 breast cancer cell line. Cancer Lett 184: 1-6, 2002.

79. Lee JH and Chung IK: Curcumin inhibits nuclear localization of telomerase by dissociating the Hsp90 co-chaperone p23 from hTERT. Cancer Lett 290: 76-86, 2010

80. Moon DO, Kang SH, Kim KC, Kim MO, Choi YH and Kim GY: Sulforaphane decreases viability and telomerase activity in hepatocellular carcinoma Hep3B cells through the reactive oxygen species-dependent pathway. Cancer Lett 295: 260-266, 2010 . 